Research Paper

\title{
Antibiosis of Trichoderma spp strains native to northeastern Mexico against the pathogenic fungus Macrophomina phaseolina
}

\author{
José Luis Hernández Mendoza, María Isabel Sánchez Pérez, \\ Juan Manuel González Prieto, Jesús DiCarlo Quiroz Velásquez, \\ Jesús Gerardo García Olivares, Homar Rene Gill Langarica
}

Instituto Politécnico Nacional, Centro de Biotecnología Genómica, Tamaulipas, México.

Submitted: September 27, 2012; Approved: May 29, 2015

\begin{abstract}
Sampling of agricultural soils from the Mexican northeastern region was performed to detect Trichoderma spp., genetically characterize it, and assess its potential use as a biologic control agent against Macrophomina phaseolina. M. phaseolina is a phytopathogen that attacks over 500 species of cultivated plants and causes heavy losses in the regional sorghum crop. Sampling was performed immediately after sorghum or corn harvest in an area that was approximately $170 \mathrm{~km}$ from the Mexico-USA border. Sixteen isolates were obtained in total. Using colony morphology and sequencing the internal transcribed spacers (ITS) 1 and 4 of 18S rDNA, 14 strains were identified as Trichoderma harzianum, T. koningiopsis and T. virens. Subsequently, their antagonistic activity against $M$. phaseolina was evaluated in vitro, and 11 isolates showed antagonism by competition and stopped $M$. phaseolina growth. In 4 of these isolates, the antibiosis phenomenon was observed through the formation of an intermediate band without growth between colonies. One strain, HTE808, was identified as Trichoderma koningiopsis and grew rapidly; when it came into contact with the M. phaseolina colony, it continued to grow and sporulated until it covered the entire petri dish. Microscopic examination confirmed that it has a high level of hyperparasitism and is thus considered to have high potential for use in the control of this phytopathogen.
\end{abstract}

Key words: Macrophomina phaseolina, antagonism, hyperparasitism, Trichoderma.

\section{Introduction}

Trichoderma spp. is a fungus that can be isolated from soil and agricultural waste and can form opportunistic interactions with and cause hyperparasitism in other fungi (Monte, 2001; Samuels, 2006). This fungus is frequently used in the textile industry, and agricultural reports have indicated that it promotes vegetable growth and facilitates the absorption of water, mineral salts, nutrients and the use of carbohydrates. It also produces secondary metabolites such as antibiotics, mycotoxins, and phytotoxins (Lifshitz et al., 1986; Benhamou and Chet, 1996; Mukherjee et al., 2006; Shoresh and Harman, 2008a, 2008b). These substances are involved in the antagonism phenomenon as a result of either competition or antibiosis or through hyperparasitism using structures called appresoria, which release enzymes (glucanases, chitobioses and chitinases) or antibiotics (viridin, gliotoxin or peptaibols) (Howell et al., 1993; Mukherjee et al., 2006). These factors encourage the use of Trichoderma spp. in controlling agricultural crop phytopathogens (Benitez et al., 2004). The increase in the number of its isolates, its high phenotypic variability, and its similarity with Hypocrea and Gliocladium complicate the identification of Trichoderma spp. through classic taxonomy. With the recent application of nucleic acid-based identification techniques, the number of described Trichoderma species has tripled. Various methods have been used in these studies, including the following sequences: (ITS) the 5 introns of the protein gene, which encodes the elongation alpha 1 (tefl) translation factor; the gene that codes for actin (gene $a c t$ ); calmodulin (gene $c a l$ );

Send correspondence to H.R.G Langarica. Instituto Politécnico Nacional, Centro de Biotecnología Genómica, Boulevard Del Maestro S/N esq. Elías Piña, Narciso Mendoza, Reynosa, 88710 Tamaulipas, México. E-mail: hgill@ipn.mx. 
and one partial exon of the gene ech42 for chitinase (Bailey and Lumsden, 1998; Castle et al., 1998; Hermosa et al., 2000; Lu et al., 2004; Vera et al., 2005; Druzhinina et al., 2006; Samuels et al., 2006). Macrophomina phaseolina (Tassi) Goid is a phytopathogenic filamentous fungus that belongs to the anamorphic Ascomycota Botryosphaeriaceae family (Crous et al., 2006; Arora et al., 2012) and produces both sclerotia and pycnidia. $M$. phaseolina is responsible for the plant disease called charcoal rot, which affects both roots and stems. M. phaseolina is widely distributed in tropical regions, specifically in areas that are subjected to water stress, where it infects hundreds of different hosts (Songa et al., 1997) and causes severe economic losses (Smith and Carvil, 1997). In Mexico, M. phaseolina is found in both the northern region, where the climate is mostly hot and dry, and in the south, where the humidity is high and where the temperatures range from $30{ }^{\circ} \mathrm{C}$ in the summer to $5^{\circ} \mathrm{C}$ in winter. This microorganism penetrates host tissues through mechanical pressure exerted by the spore germ tube and the sclerotia hyphae and through the dissolution of the cell wall via processes that are mediated by secreted enzymes (Ammon et al., 1974). Therefore, the present study was conducted to isolate native strains of Trichoderma spp. that are present in northeastern Mexican agricultural soils and to evaluate their in vitro antagonistic capacity against $M$. phaseolina.

\section{Materials and Methods}

\section{Origin of the strains}

Forty-two samples were obtained from approximately $2 \mathrm{~kg}$ of soil from the top $15 \mathrm{~cm}$ of lands recently cultivated with maize. To isolate the fungus, a technique developed in this laboratory was used, which consists of depositing $150 \mathrm{~g}$ of soil into $180-\mathrm{mL}$ Styrofoam cups, adding 10 maize seeds (Pioneer 3025) and soaking with sterile deionized water according to their needs. The cups were covered and observed for 15 days, after which they were checked to detect colonies with the typical morphology of Trichoderma spp. on the seeds and in the soil (Barnett and Hunter, 1998; Samuels et al., 2006). The isolations were performed on potato dextrose agar PDA (Difco, Sparks, $\mathrm{MD}$ ), and only the colonies with different morphological characteristics were selected for further analysis. The HMP5 strain of $M$. phaseolina used in this study was isolated from bean plants (Phaseolus vulgaris L.) in Cotaxtla, México, and was provided by the Plant Biotechnology Laboratory of the Genomics Biotechnology Center of the IPN.

\section{Antagonism}

The fungi were cultivated on PDA (Difco, Sparks, $\mathrm{MD})$ in petri dishes first individually and then in confrontation. The growth rate was measured every $12 \mathrm{~h}$. Antagonism tests were performed according to the methodology described by Acevedo (1995), which involves placing a 7-mm-diameter agar disc with a seven-day-old $M$. phaseolina mycelium and an agar disc with a four-day-old Trichoderma mycelium at adjacent points of a PDA (Difco, Sparks, MD) petri dish. Each test was replicated three times, and statistical analysis (Mean comparison, Thukey $\mathrm{p}=0.05$ ) was performed using the SAS program. Graphs were made using Microsoft Excel XP and GraphPad Prism 4.00 .

\section{DNA extraction, ITS amplification and DNA sequencing}

Isolates of Trichoderma spp. were grown in $500 \mathrm{~mL}$ Erlenmeyer flask, with $50 \mathrm{~mL}$ of Luria-Bertani broth (Difco, Sparks, MD), incubated at $27{ }^{\circ} \mathrm{C}$ with $200 \mathrm{rpm}$ shaking. The 72-h culture was centrifuged, and the biomass obtained was prepared for DNA extraction. The Hoffman and Wriston (1987) method was used, which consists of transferring the biomass to an Eppendorf tube, washing with deionized sterile water and discarding the supernatant. The cells were lysed through chemical and physical treatment and were then centrifuged at 12,000 rpm followed by RNAse addition. The obtained DNA was stored in 10:1 TE buffer at $-20{ }^{\circ} \mathrm{C}$ until used. The quantity of DNA was analyzed using a $1 \%$ agarose gel in a horizontal electrophoresis unit (Bio-Rad Laboratories Inc., Hercules, CA) at $100 \mathrm{~V}$ for $50 \mathrm{~min}$. The gel was observed in an ultraviolet transilluminator, and the image was captured with the Kodak Digital Science ${ }^{\circledR}$ 1D program (Kodak Company, Rochester, $\mathrm{NY}$ ). PCR was performed in a final volume of $50 \mu \mathrm{L}$ using $1 \mu \mathrm{L}$ of genomic DNA (50 ng), $5 \mu \mathrm{L}$ of $10 \mathrm{X}$ Buffer, $1.5 \mu \mathrm{L}$ of magnesium $(50 \mathrm{mM}), 1 \mu \mathrm{L}$ of mixed dNTPs $(10 \mathrm{mM})$, $1 \mu \mathrm{L}$ of each primer $(100 \mathrm{mM})$ and $0.4 \mu \mathrm{L}$ of the enzyme Taq DNA polymerase $(5 \mathrm{U} / \mu \mathrm{L})$, completing the volume with sterile milliQ water. For amplification of the ITS1-18S-ITS4 region of Trichoderma genome, the primer pair T/ITS1 TCTGTAGGTGAACCTGCGG and T/ITS4 TCCTCCGCTTATTGATATGC was used. The amplification program consisted of one cycle of $3 \mathrm{~min}$ at $94{ }^{\circ} \mathrm{C}$ and 35 cycles of $1 \mathrm{~min}$ at $94{ }^{\circ} \mathrm{C}, 1 \mathrm{~min}$ at $53{ }^{\circ} \mathrm{C}$ and $1 \mathrm{~min}$ at $72{ }^{\circ} \mathrm{C}$. There was a final extension step of $1 \mathrm{~min}$ at $72{ }^{\circ} \mathrm{C}$. The PCR was performed in a Peltier MJ Research Thermal Cycler ${ }^{\circledR}$ (MJ Research/Bio-Rad, Hercules, CA). We proceeded to visualize the PCR fragments on a 1\% agarose gel, adding $0.1 \mu \mathrm{L}$ SYBR gold (Thermo Fisher Scientific Inc., Waltham, MA) and $0.4 \mu \mathrm{L}$ Orange loading dye (Thermo Fisher Scientific Inc., Waltham, MA). We loaded $5 \mu \mathrm{L}$ of each sample in the gel, which was run in a horizontal electrophoresis unit (Bio-Rad Laboratories Inc., Hercules, CA) at $80 \mathrm{~V}$ for $1 \mathrm{~h}$. The gels were digitized using the Kodak Digital Science ${ }^{\circledR}$ 1D program (Kodak Company, Rochester, NY). The PCR products at a $50 \mathrm{ng} / \mu \mathrm{L}$ concentration were sequenced in the Applied System Model 3130® column sequencer (Thermo Fisher Scientific Inc., Waltham, MA). For species-level identification, the obtained data 
were compared with the reference sequences deposited in the NCBI GenBank and in the ISTH TricoOKEY databases. The Trichoderma species was determined based on concordance with these databases.

\section{Phylogenetic analysis}

After sequencing, the ITS1-18S-ITS4 region of Trichoderma isolates were compiled SeqMan software (DNASTAR Inc., Madison, WI) and edited using the BioEdit software (http://www.mbio.ncsu.edu/BioEdit/bioedit.html). Multiple alignments were performed using the ClustalW software (http://www.ebi.ac.uk/clustalw/). Each sequence type was compared by a BLAST search with those available in GenBank (http://www.ncbi.nlm.nih.gov) and those in the ISTH TricoOKEY databases to determine approximate phylogenetic affiliations. Evolutionary distances were calculated using the Kimura two-parameter model. The phylo- genetic tree was constructed with a neighbor-joining method using MEGA 4.0.

\section{Results}

A total of 42 soil samples were obtained and processed, from which 16 strains were isolated based on their similarity of morphology to Trichoderma spp. (Figure 1). These isolates were coded HTE801 to HTE816. To identify the species, sequence typing was performed, and the sequences obtained from each isolate were aligned and compared with the sequences of the GenBank database from NCBI and the TricoOKEY database from ISTH.

Isolate identification by this method showed that the strains coded from HTE801 to HTE807 and from HTE810 to HTE816 correspond to T. harzianum and that HTE808 corresponds to T. koningiopsis and HTE809 to T. virens (Figure 2). These results show that there is no association

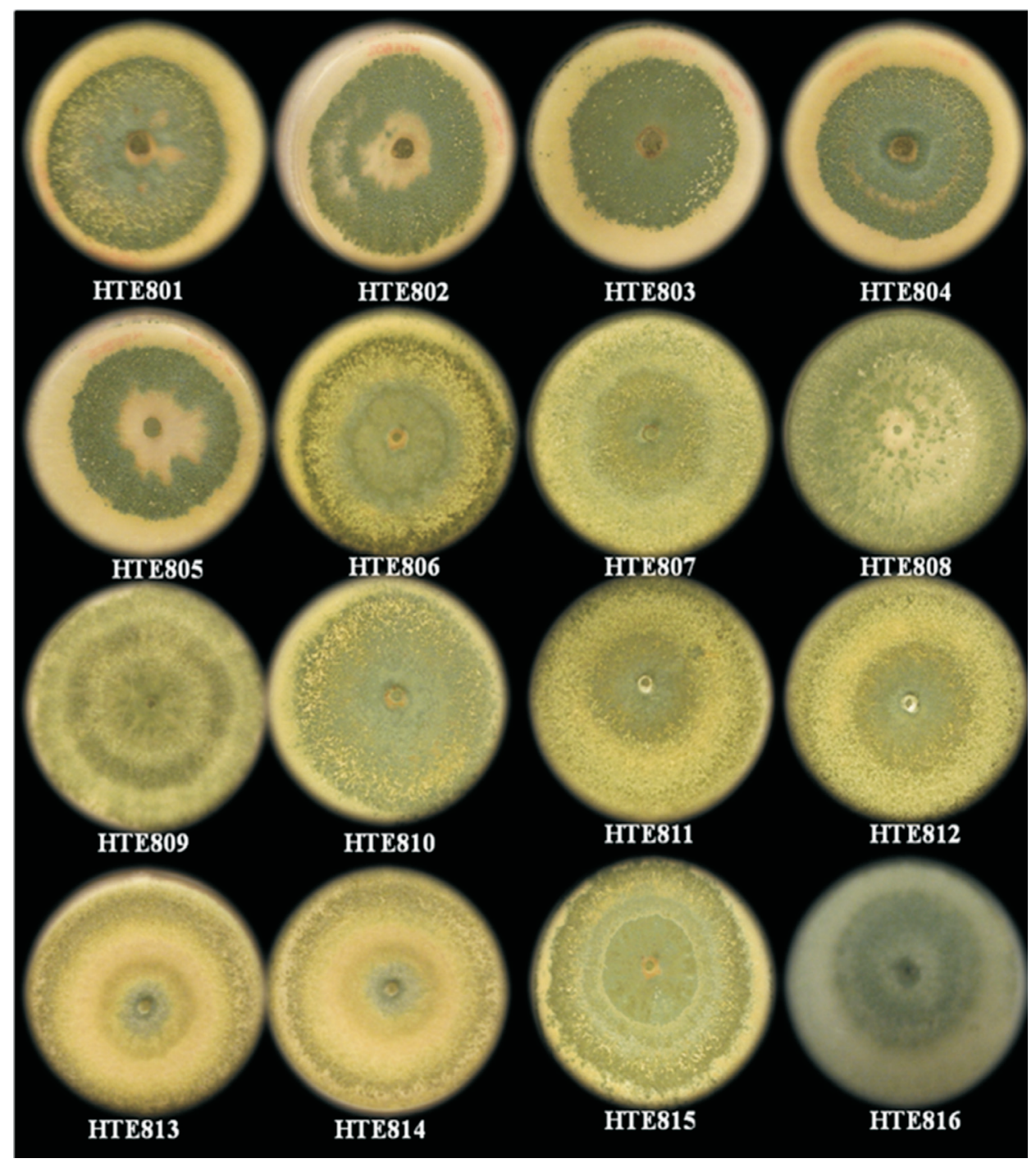

Figure 1 - Trichoderma spp. colonies obtained from soils with different crops and agronomic conditions. 


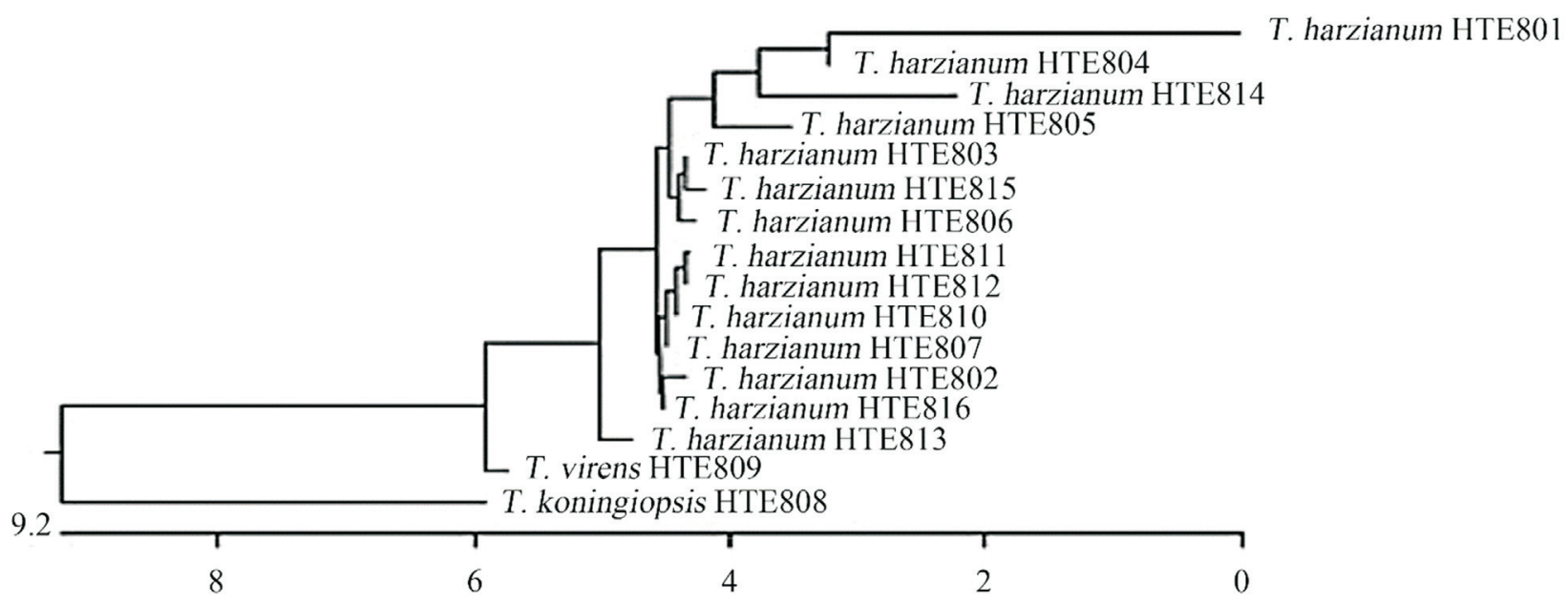

Figure 2 - Neighbor-joining phylogenetic tree of Trichoderma spp. isolates based on sequences from the ITS1-18S-ITS4 region.

among the geographical origins of the sample, the cultivated species, growing condition and the isolated fungus.

\section{Growth kinetics of assessed fungi: Trichoderma spp.}

The data obtained from the tests performed when cultivating each of the Trichoderma spp. strains individually shows that generally between 96 and $120 \mathrm{~h}$ after seeding, the mycelium completely covers the petri dish surface (Figure 3).

The growth rate curve is exponential up to $96 \mathrm{~h}$ and stabilizes thereafter. HTE801, HTE807 and HTE808 are considered fast growing because they cover the petri dish within $96 \mathrm{~h}$ after seeding, whereas a lower growth rate is observed for HTE809, with $132 \mathrm{~h}$ required post-inoculation for complete coverage. In most instances where the Trichoderma spp. is grown in the same petri dish as $M$. phaseolina, the fungus has the same developmental kinetics, except with strains such as HTE810, where a phenomenon that has not yet been reported in assays from the confrontation of Trichoderma spp. with other fungi is observed. Therefore, there are several mechanisms involved in Trichoderma antagonism, namely antibiosis, whereby the antagonistic fungus produces antibiotics and competes for nutrients. In the case of mycoparasitism, Trichoderma directly attacks the plant pathogen by excreting lytic enzymes such as chitinases, $\beta-1,3$ glucanases and proteases (Haran et al., 1996). Because the skeleton of pathogenic fungi cell walls contains chitin, glucans and proteins, enzymes that hydrolyze these components must be present in a successful antagonist to play a significant role in cell wall lysis of the pathogen. Filamentous fungal cell walls also contain lipids and proteins. It therefore was expected that antagonistic fungi synthesize proteases might act on the host cell wall (Lorito et al., 1994).

\section{Growth kinetics of assessed fungi: $M$. phaseolina}

M. phaseolina is a fungus that has an exponential kinetic growth in PDA (Difco, Sparks, MD) media and covers the entire dish $120 \mathrm{~h}$ post-inoculation. The analysis of variance was performed using a Tukey test $(p=0.05)$, which was performed by comparing the growth data of the M. phaseolina strain by itself and in antagonism with the different Trichoderma spp. strains, showed that at $60 \mathrm{~h}$ post-inoculation, the control and confrontation tests exhibit similar growth, except for strain HTE805, which develops more slowly. At the 72nd h, only nine of the evaluated strains (HTE801, HTE808, HTE813 and HTE816) came into contact with the Trichoderma spp. colonies (Figure 4). In all other treatments, contact was observed at the 84th $\mathrm{h}$ post-inoculation.

A statistical analysis of the growth kinetics between the M. phaseolina strain (Figure 4) growing by itself and in confrontation showed that strains HTE801 and HTE803 of Trichoderma spp. increased the phytopathogen colony development rate. As observed in Figure 4, for strains HTE805, HTE809 and HTE813, immediately before the contact between the colonies of M. phaseolina and Trichoderma spp., the detected growth rate of the phytopathogen decreased, which modified the exponential growth line until it stabilized.

\section{Antagonism tests}

From the antagonism tests between Trichoderma spp. and M. phaseolina, the following four phenomena were detected: antagonism through competition, antibiosis, hyperparasitism caused by Trichoderma spp. over M. phaseolina and the developmental delay of $T$. harzianum HTE810 when grown in competition with M. phaseolina. These tests were repeated three times, and the results are statistically significant. Competition is observed when the two fungi grow in the petri dish until their mycelia come into contact, 

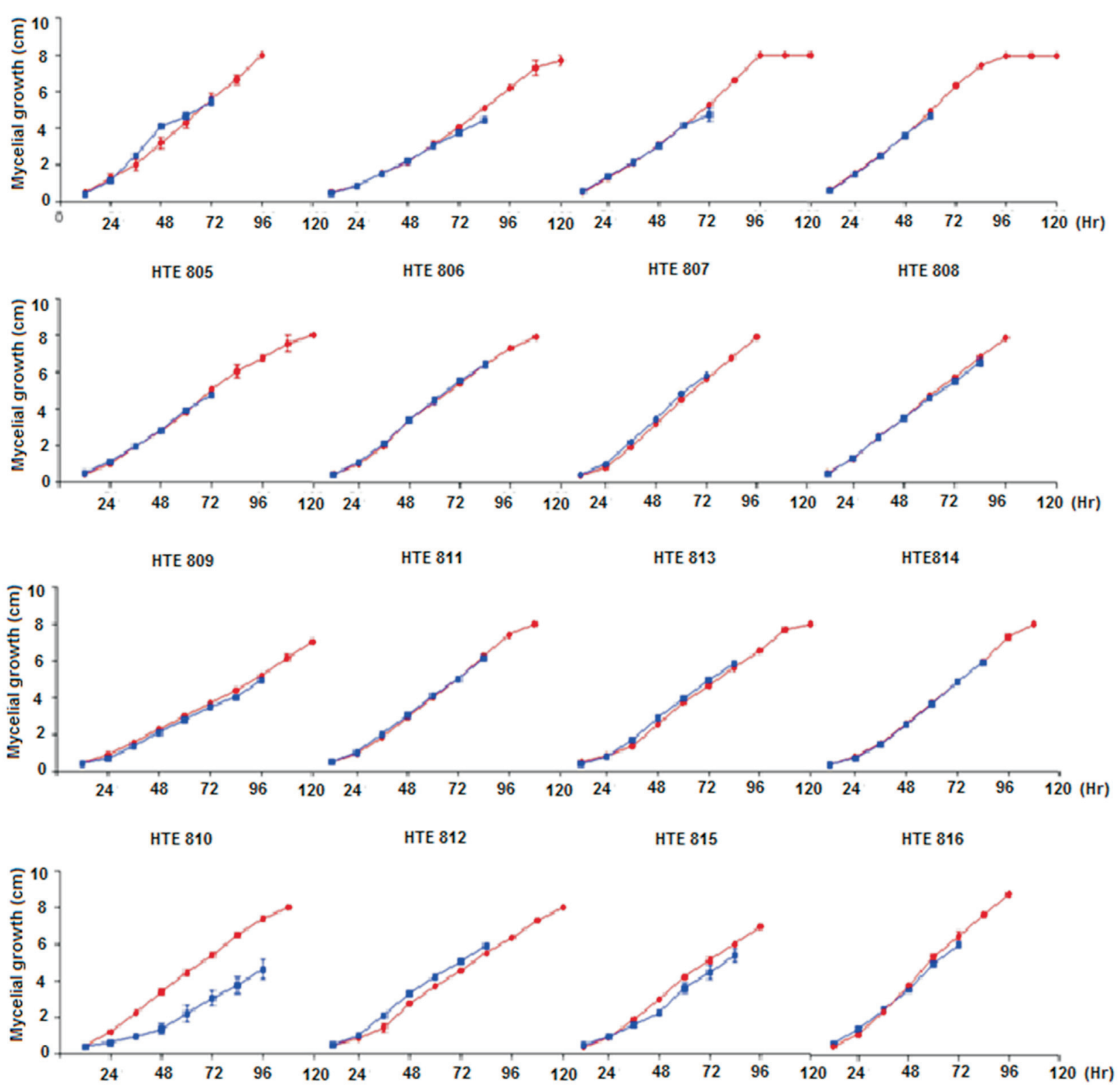

Figure 3 - Mycelial growth (cm) of Trichoderma spp. after inoculation growing by itself and in confrontation with M. phaseolina. The Percentage Inhibition of Radial Growth of M. Phaseolina (PIRGM) was determined as follows: PIRGM = [(R1-R2)/R1] x 100 where, R1 = radial growth of the pathogen and R2 = radial growth of the pathogen against Trichoderma spp; The Percentage of Radial Growth Acceleration of Trichoderma (PRGAT) was determined as follows: $\mathrm{PRGAT}=[(\mathrm{R} 2-\mathrm{R} 1) / \mathrm{R} 2]$ x 100 where, $\mathrm{R} 1=$ Radial growth of Trichoderma spp. and R2 = radial growth of Trichoderma spp. against the pathogen. Red lines indicate the growth of Trichoderma spp. and blue lines indicate the growth of Trichoderma spp. against M. phaseolina.

and the Trichoderma spp. initiates the formation of a barrier, which prevents the growth of M. phaseolina. Over time, the barrier consolidates, thereby preventing the advance of the phytopathogen (Figure 5).

\section{Antagonism through competition}

All of the $T$. harzianum and $T$. virens strains that were studied underwent antagonism by competition. Both Trichoderma species stopped the growth of the fungus $M$. phaseolina at the site of contact by forming a barrier that prevents $M$. phaseolina development.

\section{Antibiosis}

From the confrontation between the Trichoderma spp HTE 815 strain and M. phaseolina, it is observed that at $48 \mathrm{~h}$ and without contact between mycelia, a zone of growth inhibition exists and the culture medium changes color, which could be due to secondary metabolite excretion. As 

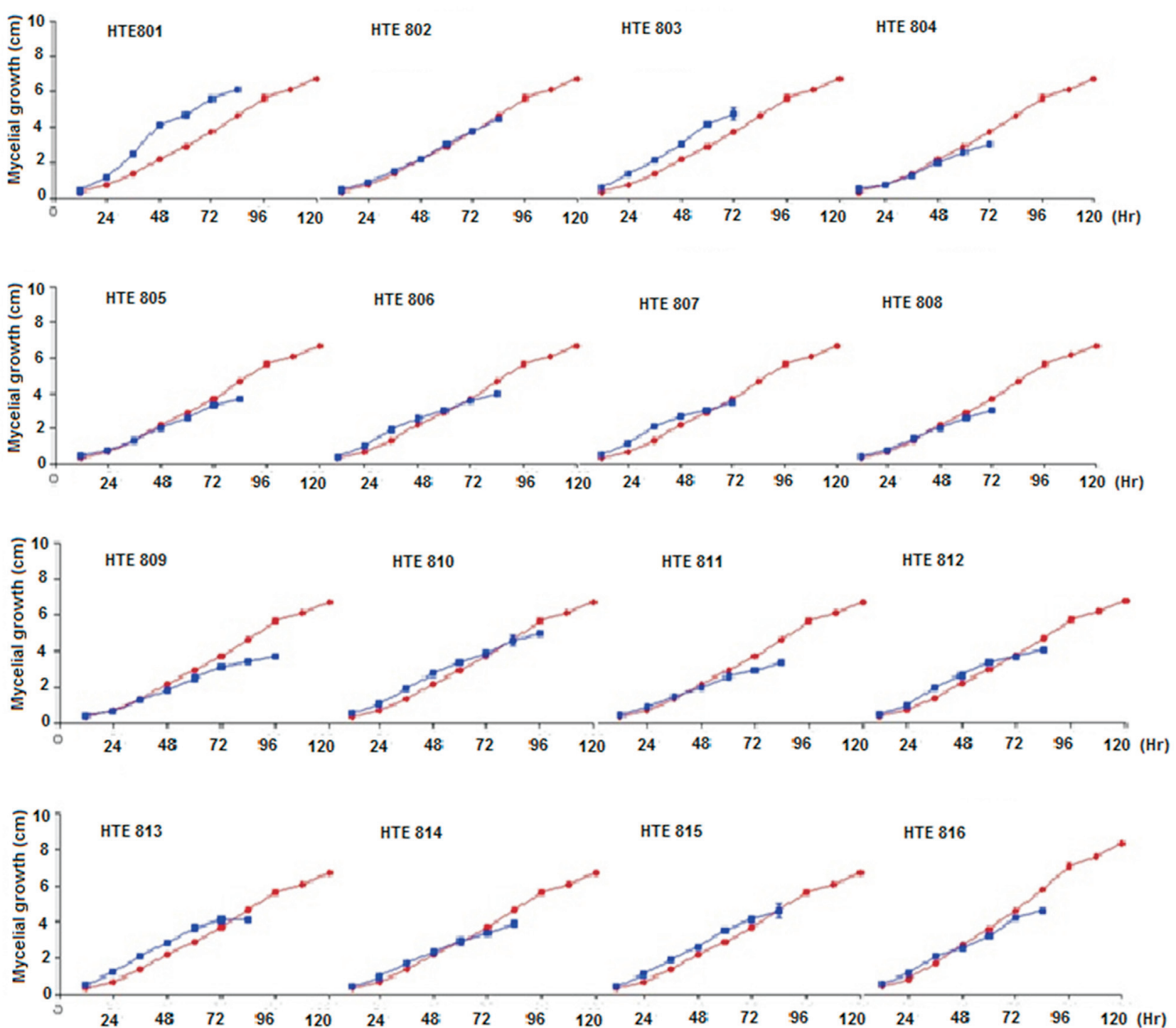

Figure 4 - Mycelial growth ( $\mathrm{cm}$ ) of M. phaseolina growing by itself and in confrontation with different Trichoderma spp strains. The Percentage Inhibition of Radial Growth of M. Phaseolina (PIRGM) was determined as follows: PIRGM = [(R1-R2)/R1] x 100 where, R1 = radial growth of the pathogen and R2 = radial growth of the pathogen against Trichoderma spp; The Percentage of Radial Growth Acceleration of Trichoderma (PRGAT) was determined as follows: PRGAT= [(R2-R1)/R2] x 100 where, R1 = Radial growth of Trichoderma spp. and R2 = radial growth of Trichoderma spp. against the pathogen. Red lines indicate the exponential growth of M. phaseolina and blue lines indicate the growth of M. phaseolina against Trichoderma spp.

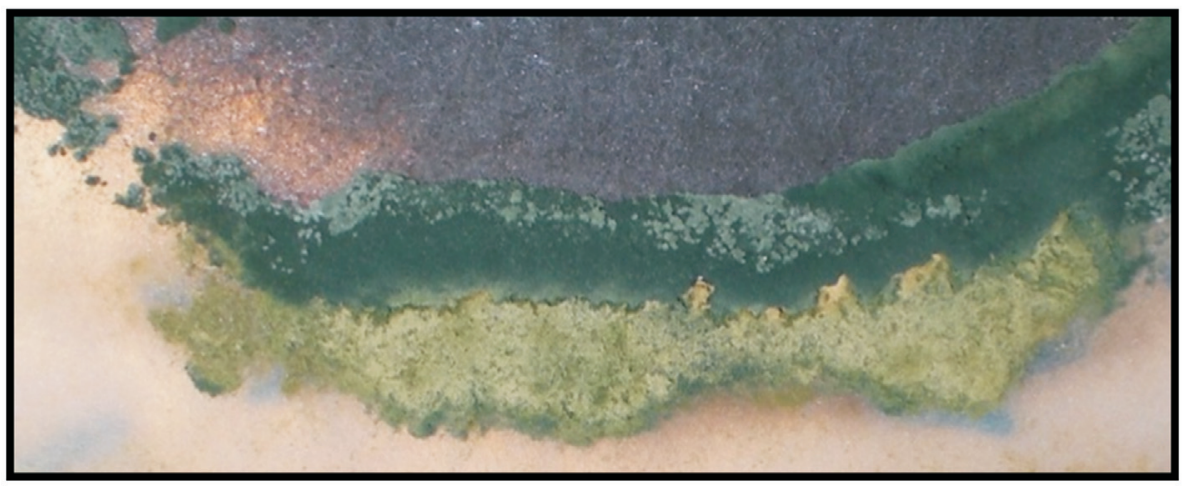

Figure 5 - Details of the growth of Trichoderma spp. (bottom green colony), showing the beginning (left) of the formation of a barrier at the contact site with the mycelium of M. phaseolina (upper dark part). 
shown in Figure 6, a narrow band without growth can form between the fungi, even when they are far from physical contact.

\section{Hyperparasitism}

Mycoparasitism involves morphological changes, such as coiling and formation of appressorium-like structures, which serve to penetrate the host. Differential antagonistic activity has been observed for various Trichoderma spp., which demonstrates semi-specificity in the interaction of Trichoderma with M. phaseolina. Our results revealed that of the 16 strains tested, only T. koningiopsis (HTE808) shows antagonism by hyperparasitism. Microscopically, $T$. koningiopsis hyphae are rolled into phytopathogenic $M$. phaseolina hyphae. This is a desirable trait for agricultural purposes because this strain (HTE808) has potential for use in phytopathogen control.

\section{Discussion}

The isolates obtained showed the formation of concentric rings that are typical of Trichoderma spp. colonies, where the green color of the conidia is interleaved with the white of the mycelium, which is consistent with the characteristics previously described for this fungus (Barnett and Hunter, 1998; Druzhinina et al., 2006; Samuels, 2006). However, although the colony morphology serves to identify fungi of this genus, it is insufficient to distinguish the species, which makes it necessary to confirm the species through molecular methods (Ospina et al., 1999; Druzhinina et al., 2005, 2006). The identification of the isolates in this study yielded three species, of which T. harzianum was the most frequently sampled. The presence of $T$. harzianum had already been reported in this region of the country (Larralde-Corona et al., 2008), and it is the species with the

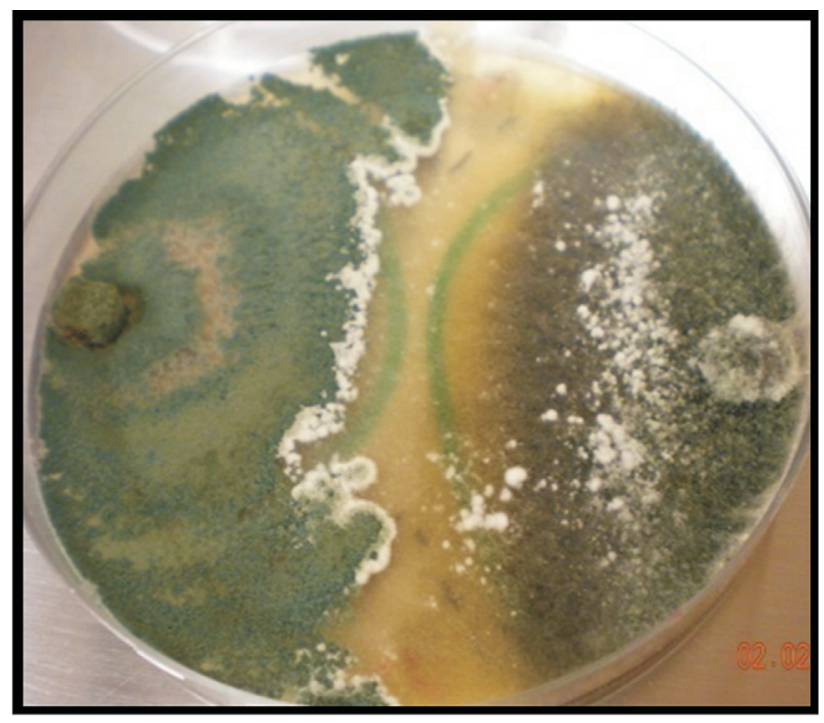

Figure 6 - Growth and sporulation of Trichoderma spp. on M. phaseolina and the intersection point between them. widest distribution (Hermosa et al., 2000; Harman et al., 2004). Additionally, the TichoOKEY database could only be used to compare the sequences of some T. harzianum, $T$. virens and T. koningiopsis strains because, for sequencing the strains HTE801, HTE804, HTE805, HTE810 and HTE814, it was necessary to draw upon the NBCI GenBank database, where the identification was corroborated. The antagonism phenomenon observed in these isolates, where the strains of Trichoderma spp. did not allow the growth of the M. phaseolina colonies, confirm the competition, antibiosis and hyperparasitism phenomena that have been reported for Trichoderma spp. (Hjeljord and Tronsmo, 1998; Hermosa et al., 2000; Benitez et al., 2004; Harman, 2006; Hoitink et al., 2006). Two phenomena that have not been previously reported were also observed; the first involves a strong decrease in the growth of the $T$. harzianum colony strain HTE 810 when cultivated in confrontation tests with M. phaseolina (Figure 3). The other phenomenon detected is counter to the previous model of interaction, namely the induction rather than repression, of $M$. phaseolina colony growth in the presence of the $T$. harzianum strain HTE801 and, to a lesser extent, HTE803. In both cases, the acceleration is statistically significant (Tukey, $\mathrm{p}=0.05$; Figure 3 ).

Antagonism through antibiosis was detected in strains HTE807, HTE810, HTE815 and HTE809 of Trichoderma spp., which show growth-free spaces between both fungi, as well as a change in coloring in the culture medium. These strains correspond to T. harzianum and $T$. virens, respectively. The growth-free zone is possibly due to Trichoderma spp. producing metabolites such as viridin and its derivatives, which function as antimicrobials (Benitez et al., 2004; Harman, 2006; Hoitink et al., 2006; Vinale et al., 2008). Finally, it was observed in $T$. harzianum strain HTE810 that the M. phaseolina strain HMP5 has a statistically significantly decreased growth rate, which was the initial impetus of these trials. We have not found reports of this response against $T$. harzianum.

\section{Conclusions}

This sampling shows that Trichoderma is a fungus that can be isolated from soil and that there is no relationship between the species and the conditions under which agriculture is carried out in this region. Of the detected fungi, $T$. harzianum is the most frequent species, with $T$. koningiopsis and $T$. virens following in frequency. From the antagonism test results, $T$. harzianum and $T$. virens show antagonistic activity through space competition, while T. koningiopsis showed a high level of hyperparasitism on M. phaseolina, demonstrating a strong potential for use as a control agent. The M. phaseolina HMP5 strain decreased the $T$. harzianum HTE810 growth when cultivated in a confrontation test. 


\section{Acknowledgments}

We would like to thank the Instituto Politecnico Nacional and Patronato para la Investigacion Fomento y Sanidad Vegetal A.C. for financial support for this project. We would also like to thank the Laboratorio de Biotecnologia Vegetal of CBG-IPN for providing the $M$. phaseolina strain used in this study. Hernandez-Mendoza (JSHM), J.M Gonzalez-Prieto (JMGP) and H.R Gill-Langarica (HRGL) are SNI fellows, and supported by COFAA and EDI-IPN scholarships.

\section{References}

Acevedo R (1995) Control biológico de la pudrición blanca del ajo (Sclerotium cepivorum Berk) utilizando el micoparasitismo Trichoderma spp. San Cristóbal, Venezuela. Undergraduate Dissertation, Universidad Nacional Experimental de Táchira, 109 pp.

Ammon V, Wyllie TD, Brown Jr MF (1974) An ultrastructural investigation of pathological alterations induced by Macrophomina phaseolina (Tassi) Goid in seedlings of soybean, [Glycine max (L.) Merrill.] Physiol Plant Pathol 4:1-2.

Arora P, Dilbaghi N, Chaudhury A (2012) Opportunistic invasive fungal pathogen Macrophomina phaseolina prognosis from immunocompromised humans to potential mitogenic RBL with an exceptional and novel antitumor and cytotoxic effect. Eur J Clin Microbiol Infect Dis 31:101-107.

Bailey BA, Lumsden RD (1998) Direct effects of Trichoderma and Gliocladium on plant growh and resistance to pathogens. In: Harman GE, Kubiek CP (eds) Trichoderma and Gliocladium, Vol. 2. Enzymes, Biological Control and Commercial Applications. Taylor and Francis, London, pp. 185-204.

Barnett HL, Hunter BB (1998) Illustrated Genera of Imperfect Fungi. $4^{\mathrm{a}}$ ed. Aps Press, USA.

Benhamou N, Chet I (1996) Parasitism of sclerotia of Sclerotium rofsii by Trichoderma harzianum: Ultrastructural and cytochemical aspects of the interaction. Phytopathology 86:405-416.

Benitez T, Rincón AM, Limon MC et al. (2004) Biocontrol mechanisms of Trichoderma strains. Int Microbiol 7:249-260.

Castle A, Speranzini D, Rghel N et al. (1998) Morphological and molecular identification of Trichoderma isolates on North American Mushroom farms. Appl Environ Microbiol 64:133-137.

Crous PW, Slippers B, Wingfield MJ (2006) Phylogenetic lineages in the Botryosphaeriaceae. Stud Mycol 55:235-253.

Druzhinina IS, Kopchinskiy AG, Komon M et al. (2005) An oligonucleotide barcode for species identification in Trichoderma and Hypocrea. Fungal Genet Biol 42:813-828.

Druzhinina IS, Kopchinskiy AG, kubicek CP (2006) The first 100 Trichoderma species characterized by molecular data. Mycoscience 47:55-64.

Haran S, Schickler H, Chet I (1996) Molecular mechanisms of lytic enzymes involved in the biocontrol activity of Trichoderma harzianum. Microbiology 142:2321-2331.

Harman GE (2006) Overview of mechanisms and uses of Trichoderma spp. Phytopathology 96:190-194.
Harman GE, Howell CR, Viterbo A et al. (2004) Trichoderma species opportunistic avirulent plant symbionts. Nat Rev Microbiol 2:43-56.

Hermosa MR, Grondona I, Iturriaga EA et al. (2000) Molecular characterization and identification of biocontrol isolates of Trichoderma spp. Appl Environ Microbiol 66:1890-1898.

Hjeljord L, Tronsmo A (1998) Trichoderma and Gliocladium in biological control: an overview. In: Harman GE, Kubicek CP (eds) Trichoderma and Gliocladium, Vol 2. Enzymes, Biological Control and Commercial Applications. Taylor and Francis, London, pp 131-151.

Hoffman CS, Wriston F (1987) A ten-minute DNA preparation from yeast efficiently releases autoctonous plasmids for transformation of Escherichia coli. Gene 57:267-272.

Hoitink HAJ, Maden LV, Dorrance AE (2006) Systemic resistance induced by Trichoderma spp.: Interactions between the host, the pathogen, the biocontrol agent, and soil organic matter quality. Phytopathology 96:196-189

Howell C, Stipanovic R, Lumsden R (1993) Antibiotic production by strains of Gliocladium virens and its relation to biocontrol of cotton seedling diseases. Biocontrol Sci Technol 3:435-441.

Larralde-Corona CP, Santiago-Mena MR, Sifuentes-Rincon AM et al. (2008) Biocontrol potential and polyphasic characterization of novel native Trichoderma strains against Macrophomina phaseolina isolated from sorghum and common bean. Appl Microbiol Biotechnol 80:167-177.

Lifshitz R, Windhan MT, Baker R (1986) Mechanism of biological control of preemergence damping-off of pea by seed treatment with Trichoderma spp. Phytopathology 76:720-725.

Lorito M, Hayes CK, Di Pietro A et al. (1994) Purification, characterization and synergistic activity of a glucan $1,3-\beta$-glucosidase and an $\mathrm{N}$-acetylglucosaminidase from $T$. harzianum. Phytopathology 84:398-405.

Lu BS, Druzhinina IS, Fallah P et al. (2004) Hypocrea/Trichoderma species with pachybasium-like conidiophores: Teleomorphs for $T$. minutisporum and $T$. polysporum and their newly discovered relatives. Mycologia 96:310-342.

Monte E (2001) Understanding Trichoderma: Between biotechnology and microbial ecology. Int Microbiol 4:1-4.

Mukherjee M, Horwitz BA, Sherkhane PD et al. (2006) A secondary metabolite biosynthesis cluster in Trichoderma virens evidence from analysis of genes underexpressed in a mutant of defective in morphogenesis and antibiotic production. Current Genet 50:193-202.

Ospina GMD, Royse DJ, Chen X et al. (1999) Molecular phylogenetic analysis of biological control strains of Trichoderma harzianum and other biotypes of Trichoderma spp. associated with Mushroom Green Mold. Phytopathology 89:308313.

Samuels GJ (2006) Trichoderma: Systematics, the sexual state, and ecology. Phytopathology 96:195-206.

Samuels GJ, Dodd SL, Lu BS et al. (2006) The Trichoderma koningii aggregate species. Stud Mycol 56:67-133.

Shoresh M, Harman GE (2008a) The molecular basis of shoot responses of maize seedlings to Trichoderma harzianum T22 inoculation of the root: A proteomic approach. Plant Physiol 147:2147-2163. 
Shoresh M, Harman GE (2008b) The relationships between increased grow and resistance induced in plants by root colonizing microbes. Plant Signal \& Behavoir 3:737-739.

Smith GS, Carvil ON (1997) Field screening of commercial and experimental soybean cultivars for their reaction to Macrophomina phaseolina. Plant Dis 81:363-368.

Songa W, Hillocks RJ, Mwango'mbe AW et al. (1997) Screening common bean accessions for resistance to charcoal rot (Macrophomina phaseolina) in Eastern Kenya. Exp Agric 33:459-468.
Vera R, Moreno B, Acevedo R et al. (2005) Caracterización de aislamientos de Trichoderma spp. por tipo de antagonismo y electroforesis de isoenzimas. Fitopatol Venez 18:2-8.

Vinale F, Sivasithamparamb K, Ghisalbertic ML et al. (2008) Trichoderma plant pathogen interactions. Soil Biol Biochem 40:1-10.

Associate Editor: Carlos Pelleschi Taborda

All the content of the journal, except where otherwise noted, is licensed under a Creative Commons License CC BY-NC. 